\title{
Features of addictive behavior of students with different levels of health
}

\author{
Nikolay Bokhan, Irina Karaush, Bairma Dashieva, Irina Kupriyanova \\ Mental Health Research Institute, Tomsk National Research Medical Center, Russian \\ Academy of Sciences, Tomsk, Russia
}

Prevalence of substance use at adolescent age, predisposing to addictive behavior attitudes, specific of puberty period influence future health of young people and determine the priority of investigations of risks associated with formation of addictions.

Objective: to study psychological characteristics and characteristics of addictive behavior of students in general education and correctional schools.

Materials and Methods. With continuous sampling method three groups were formed:

Study group $1(\mathrm{n}=198)$ - students of general education schools aged 12-17 years (85 - urban, 113 - rural).

Study group 2 ( $\mathrm{n}=223)$ - students of correctional schools aged 12-17 years with severe hearing and visual impairments (sensorineural deafness of III-IV degree, deafness, congenital abnormalities of organ of vision) causing study in specialized schools (adolescents with health limitations).

Study group $3(\mathrm{n}=-165)$ - parents of children with health limitations studying in specialized schools in connection with the index disease: cerebral palsy, hearing impairments, mental retardation of mild degree; 75 fathers and 90 mothers.

Methods: clinical, psychological, statistical. State-Trait Anxiety Inventory by Ch. Spielberger - Yu. Khanin, Child Depression Inventory by $M$. Kovacs, Self-Compiled Questionnaire for detection of substance use

Results.

\begin{tabular}{|c|c|c|c|c|c|c|c|c|}
\hline & tal & 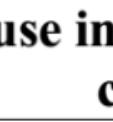 & $\begin{array}{l}\text { oys s } \\
\text { rrect }\end{array}$ & $\begin{array}{l}\text { dyıng } \\
\text { al se }\end{array}$ & $\begin{array}{l}\text { n gen } \\
\text { ols }\end{array}$ & & & \\
\hline \multirow[t]{2}{*}{$\begin{array}{l}\text { Addictive } \\
\text { behavior }\end{array}$} & \multicolumn{2}{|c|}{$\begin{array}{c}\text { Students of } \\
\text { urban schools, } \\
n=45\end{array}$} & \multicolumn{2}{|c|}{$\begin{array}{c}\text { Students of } \\
\text { rural schools, } \\
n=70\end{array}$} & \multicolumn{2}{|c|}{$\begin{array}{c}\text { Students of } \\
\text { correctional } \\
\text { schools, } n=131\end{array}$} & \multicolumn{2}{|c|}{$\begin{array}{c}\text { In total, } \\
\mathrm{n}=246\end{array}$} \\
\hline & abs & $\%$ & abs & $\%$ & abs & $\%$ & abs & $\%$ \\
\hline Smoking & 4 & 8.9 & 8 & 11.1 & 64* & 48.8 & 76 & 30.9 \\
\hline Alcohol use & 6 & 13.3 & 7 & 10 & 22 & 16.8 & 35 & 14.2 \\
\hline Drug use & 2 & 4.4 & 5 & 7.1 & 0 & 0 & 7 & 2.8 \\
\hline
\end{tabular}
rural and correctional schools $\left(\chi^{2}=14.61, p=0.0001, d f=1\right)$

\begin{tabular}{|c|c|c|c|c|c|c|c|c|}
\hline & $\tan$ & & rrect & $\begin{array}{l}\text { ayme } \\
\text { lal sc }\end{array}$ & $\begin{array}{l}n \text { gen } \\
\text { gols }\end{array}$ & & & \\
\hline \multirow[t]{2}{*}{$\begin{array}{l}\text { Addictive } \\
\text { behavior }\end{array}$} & \multicolumn{2}{|c|}{$\begin{array}{c}\text { Students of } \\
\text { urban schools, } \\
n=40\end{array}$} & \multicolumn{2}{|c|}{$\begin{array}{c}\text { Students of } \\
\text { rural schools, } \\
n=43\end{array}$} & \multicolumn{2}{|c|}{$\begin{array}{c}\text { Students of } \\
\text { correctional } \\
\text { schools, } n=92\end{array}$} & \multicolumn{2}{|c|}{$\begin{array}{c}\text { In total, } \\
\mathrm{n}=175\end{array}$} \\
\hline & abs & $\%$ & abs & $\%$ & abs & $\%$ & abs & $\%$ \\
\hline Smoking & 7 & 17.5 & 0 & 0 & 28 & 30.4 & 35 & 20 \\
\hline Alcohol use & $12 *$ & 30 & 2 & 4.7 & 15 & 16.3 & 29 & 16.6 \\
\hline Drug use & 4 & 10 & 1 & 2.3 & 0 & 0 & 5 & 2.9 \\
\hline
\end{tabular}

Addictive behavior of adolescents with sensory impairments

\begin{tabular}{|c|c|c|c|c|}
\hline \multirow{2}{*}{} & \multicolumn{2}{|c|}{$\begin{array}{c}\text { Visually impaired } \\
(\mathrm{n}=102)\end{array}$} & \multicolumn{2}{c|}{$\begin{array}{c}\text { With hearing impairments, deaf } \\
(\mathrm{n}=121)\end{array}$} \\
\cline { 2 - 5 } & $\mathrm{abs}$ & $\%$ & $\mathrm{abs}$ & $\%$ \\
\hline Smoking & 47 & 46 & 45 & 37.2 \\
\hline Alcohol & 22 & 21.6 & 15 & 12.4 \\
\hline
\end{tabular}

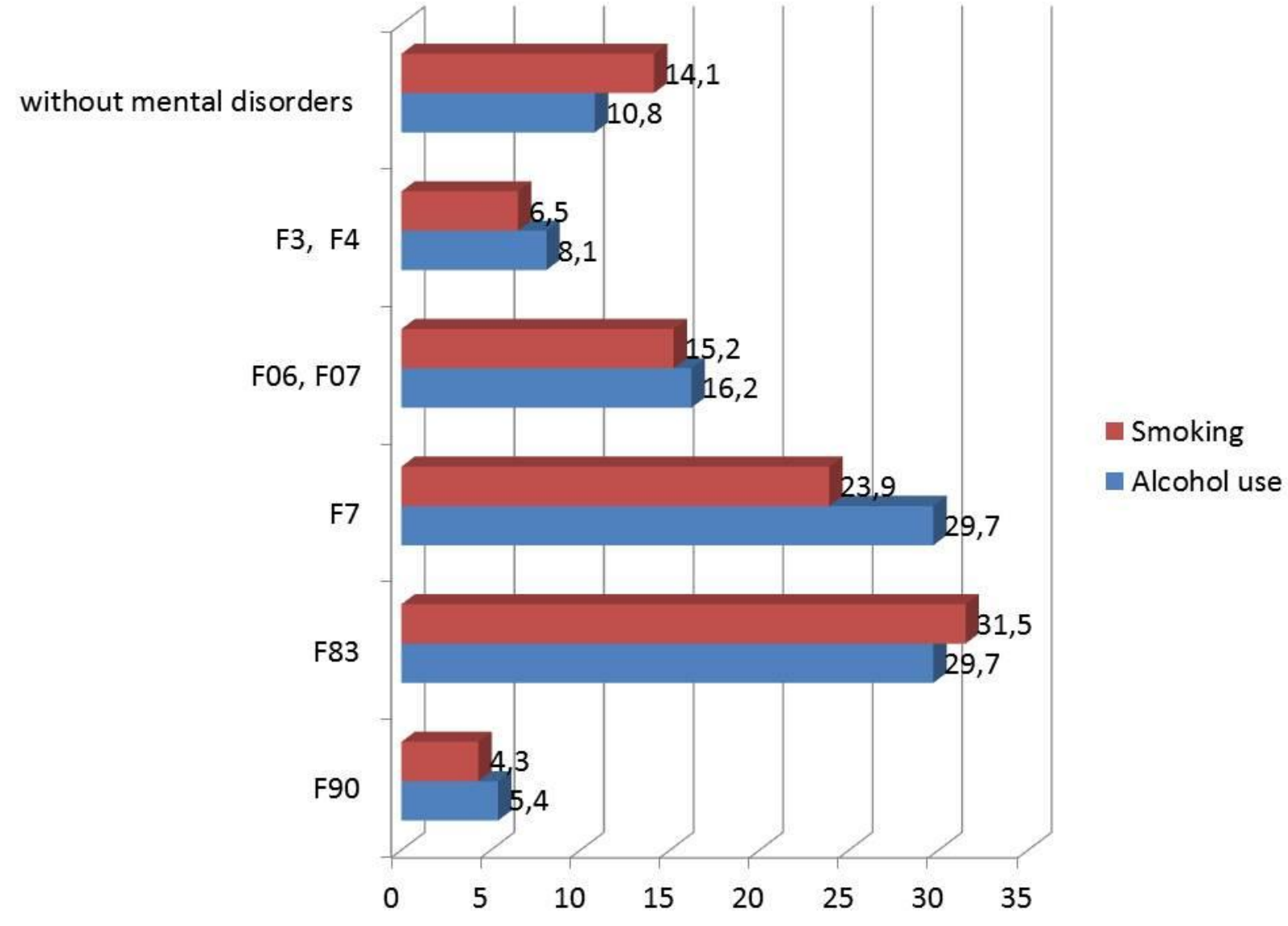

Smoking and alcohol use in adolescents with sensory and mental disorders, \%. (Group without mental disorders - 48 persons, with neurotic and affective disorders - 12 persons, organic disorders 39 persons, disorders of mental development -80 persons, mental retardation - 35 persons).

\section{Conclusion.}

Distinguished features of addictive behavior of adolescents of different categories were as follows:

- as a whole, every third boy and fifth girl smoke, every seventh boy and sixth girl use alcohol, every $36^{\text {th }}$ adolescent irrespective from gender recognize trying drugs;

- there are no differences in smoking and alcohol use in persons with high and low/middle level of risk of development of depression;

- among adolescents with health limitations persons with comorbid mental disorder use alcohol more often, for them low level of formation a of abstract-logical thinking and ability to predict consequences;

- girls studying in urban schools use alcohol more often compared with rural and students of correctional schools and boys with sensory disorders smoke more often compared with students of general education schools;

- for alcohol using adolescents infantilism, low level of demands, narrow focus of interest and possibilities of self affirmation, influence of "delinquent" peers;

- alexithymic characteristics are found more often in adolescents using alcohol;

- alcohol abuse by parents, especially by mothers in adolescents with health limitations is associated with major likelihood of substance use in their children. 